\title{
Keragaman pangan, pola asuh makan dan kejadian stunting pada balita usia 24-59 bulan
}

\author{
Novita Nining Widyaningsih ${ }^{1 *}$, Kusnandar $^{2}$, Sapja Anantanyu ${ }^{3}$
}

\section{ABSTRACT}

Background: Stunting is a chronic nutritional problem that occurs due to lack of nutrient intake over a long period of time, causing growth disturbances which are marked by an appropriate height for age. The incidence of stunting in toddlers is influenced by the low access to food both in terms of quantity and quality. In addition, it is also influenced by the feeding parenting from the mother, particularly in the feeding practice of the children.

Objective: To determine the relationship between food diversity and feeding practice with the incidence of stunting in toddlers aged 24-59 months in Bayat Sub-district, Klaten Regency.

Method: The study design used was a cross-sectional study. The study was conducted in Bayat Sub-district, Klaten Regency, with a total subject of 100 toddlers aged 24-59 months. The simple random sampling technique was used for sampling. Birth weight and birth length data as seen from KMS book. The food diversity was measured using IDDS (Individual Dietary Diversity Score) questionnaire and feeding practise was obtained through interviews measured using structured questionnaire. The data was then analyzed using bivariate (chi square) and multivariate (logistic regression) analysis.

Results: This study showed that the $41 \%$ of toddlers aged 24-59 months are stunted. Chi square test showed that there were a relationship between birth length, feeding practice and food diversity with stunting $(p \leq 0.05)$. The result of multivariate analysis showed that there was a relationship between food diversity with stunting ( $p=0,029$, OR=3,213, 95\% Cl: 1,123-9,189).

Conclusion: There is a relationship between birth length, feeding practice, and food diversity with stunting. The most dominant risk factor for stunting was food diversity.

Keywords: Stunting, Food Diversity, Feeding Practice

\section{ABSTRAK}

Latar Belakang: Stunting merupakan permasalahan gizi kronis yang terjadi karena asupan zat gizi yang kurang dalam jangka waktu yang lama, sehingga menyebabkan gangguan pertumbuhan yang ditandai dengan tinggi badan yang tidak sesuai dengan umur. Kejadian stunting pada balita dipengaruhi oleh rendahnya kemampuan akses terhadap makanan baik dari segi kuantitas maupun kualitas. Selain itu juga dipengaruhi oleh pola asuh makan yang diterapkan oleh ibu terutama pada praktek memberian makan pada balita.

Tujuan: Untuk mengetahui hubungan keragaman pangan dan pola asuh makan dengan kejadian stunting pada balita usia 24 59 bulan di Kecamatan Bayat, Kabupaten Klaten.

Metode: Desain penelitian yang digunakan adalah cross sectional study. Penelitian dilaksanakan di Kecamatan Bayat, Kabupaten Klaten dengan jumlah subjek 100 balita yang berusia 24-59 bulan. Teknik pemilihan subjek dengan teknik simple random sampling. Data berat badan lahir dan panjang badan lahir diperoleh dari buku KMS. Keragaman pangan diukur menggunakan kuesioner IDDS (Individual Dietary Diversity Score) dan pola asuh makan diperoleh melalui wawancara menggunakan kuesioner terstruktur. Data kemudian dianalisis menggunakan analisis bivariate (chi square) dan analisis multivariate (regresi logistik).

Hasil: Penelitian ini menunjukkan bahwa $41 \%$ balita usia $24-59$ bulan mengalami stunting. Uji chi square menunjukkan bahwa terdapat hubungan antara panjang badan lahir, pola asuh makan dan keragaman pangan dengan stunting $(p \leq 0,05)$. Hasil analisis multivariate menunjukkan bahwa terdapat hubungan antara keragaman pangan dengan stunting $(p=0,029$, OR=3,213, 95\% Cl: 1,123-9,189)

Kesimpulan: Terdapat hubungan antara panjang badan lahir, pola asuh makan dan keragaman pangan dengan stunting. Faktor resiko kejadian stunting yang paling dominan adalah keragaman pangan.

Kata Kunci: Stunting, Keragaman Pangan, Pola Asuh Makan

\section{PENDAHULUAN}

Stunting merupakan permasalahan gizi di dunia, ada 165 juta balita di dunia dalam kondisi pendek (stunting). Delapan puluh persen balita stunting tersebar pada 14 negara di dunia dan Indonesia menduduki

\footnotetext{
${ }^{1}$ Progam Studi Ilmu Gizi, Pascasarjana Universitas Sebelas Maret. Jalan Ir. Sutami No. 36A, Jebres, Kota Surakarta, Jawa Tengah 57126

Penulis Penanggungjawab.

${ }^{2}$ Agribisnis, Fakultas Pertanian, Universitas Sebelas Maret. Jalan Ir. Sutami No. 36A, Jebres, Kota Surakarta, Jawa Tengah 57126

${ }^{3}$ Penyuluhan dan Komunikasi Pertanian, Fakultas Pertanian, Universitas Sebelas Maret. Jalan Ir. Sutami No. 36A, Jebres, Kota Surakarta, Jawa Tengah 57126

* Korespondensi: E-mail:novita.nining@yahoo.com. No Hp. 081310347641
} 
rangking ke lima negara dengan jumah stunting terbesar. ${ }^{1}$ Data stunting di Indonesia menunjukkan bahwa prevalensi stunting secara nasional terjadi peningkatan dari 35,6\% (2010) menjadi 37,2 \% (tahun 2013). Kondisi tersebut menggambarkan bahwa sekitar 8,9 juta anak Indonesia mengalami pertumbumbuhan tidak maksimal atau satu dari tiga anak mengalami stunting. ${ }^{2}$ Hasil Pemantauan Status Gizi (PSG) tahun 2017 menunjukkan bahwa persentase balita stunting pada kelompok balita $(29,6 \%)$ lebih besar jika dibandingkan dengan usia baduta $(20,1 \%){ }^{3}$ Hal ini terjadi karena pada usia tersebut balita sudah tidak mendapatkan ASI dan balita mulai menyeleksi (memilih) makanan yang dimakan., ${ }^{4,5}$ Oleh karena itu pada masa ini sangat penting peran orang tua terutama ibu dalam memberian makan kepada balita.

Pola asuh makan yang diterapkan oleh ibu akan berpengaruh terhadap pertumbuhan dan perkembangan balita karena kekurangan gizi pada masa balita akan bersifat irreversible (tidak dapat pulih), sehingga pada masa ini balita membutuhkan asupan makan yang berkualitas. ${ }^{6} \mathrm{Hal}$ ini diperkuat dengan penelitian yang dilakukan di Nusa Tenggara Timur bahwa pola asuh makan yang diterapkan oleh ibu akan menentukan status gizi balita. Semakin baik pola asuh makannya maka semakin baik pula status gizinya. ${ }^{7}$ Pola asuh makan yang baik dicerminkan dengan semakin baiknya asupan makan yang diberikan kepada balita. Asupan makan yang dinilai secara kualitatif digambarkan melalui keragaman konsumsi pangan. ${ }^{8}$ Keragaman pangan mencerminkan tingkat kecukupan gizi seseorang. ${ }^{9}$

Keragaman pangan merupakan salah satu masalah gizi utama di negara-negara berkembang seperti Indonesia. Pada Negara berkembang mayoritas asupan makanannya didominasi oleh makanan sumber kalori dan kurangnya asupan makanan hewani, buah-buahan, sayur-sayuran. ${ }^{10}$ Beberapa penelitian telah melaporkan bahwa keragaman pangan yang rendah berhubungan dengan peningkatan resiko stunting dan masalah gizi lainya seperti overweight, dislipidemia, sindrom metabolik. ${ }^{1-14}$ Pada jangka panjang kejadian stunting pada balita akan berdampak pada penurunan fungsi kognitif, gangguan memori, prestasi sekolah yang buruk yang ketika dewasa akan menurunkan pendapatan dan produktivitas kerja. ${ }^{15}$ Hasil penelitian yang dilakukan dilakukan di Kenya dan Nigeria menyatakan bahwa keragaman pangan balita yang diukur dengan menggunakan IDDS (Individual Dietary Diversity Score) dapat digunakan sebagai prediktor kejadian stunting pada balita. ${ }^{16,17}$

Penelitian terkait stunting sudah banyak dilakukan di Indonesia. Mayoritas penelitian tersebut mengkaji hubungan antara asupan zat gizi makro dan mikro dengan kejadian stunting, masih sedikit penelitian yang mengkaji terkait keragaman pangan. Beberapa penelitian terkait keragaman pangan yang dilakukan di
Indonesia adalah penelitian yang dilakukan oleh Wirawan dan Rahmawati di Kota malang. Hasil penelitian tersebut menunjukkan bahwa keragaman pangan yang diukur dengan HDDS (Household Dietary Diversity Score) tidak berhubungan dengan stunting. Hal ini terjadi karena HDDS digunakan untuk melihat kemampuan rumah tangga untuk dapat mengakses makanan yang beragam sehingga kurang mampu menggambarkan kejadian stunting pada balita. ${ }^{18}$ Penelitian yang dilakukan Paramashanti et al di Kabupaten Bantul menyatakan bahwa keragaman pangan yang diukur dengan kuesioner IDDS (Individual Dietary Diversity Score) dapat menurunkan resiko stunting pada balita 6-24 bulan. ${ }^{19}$ Perbedaan penelitian ini dengan penelitian yang dilakukan oleh Wirawan dan Rahmawati adalah pada cara pengukuran keragaman pangan, pada penelitian ini keragaman pangan diukur dengan menggunakan kuesioner IDDS, sedangkan perbedaan penelitian ini dengan penelitian Paramashanti et al terletak pada subjek penelitian. Pada penelitian ini subjek penelitiannya difokuskan pada balita usia 24-59 bulan karena persentase balita stunting pada kelompok balita lebih tinggi jika dibandingkan kelompok baduta, ${ }^{3}$ selain itu pada usia tersebut balita sudah tidak mendapatkan ASI. Kondisi ini menyebabkan pola asuh makan yang dilakukan oleh ibu akan berdampak terhadap kejadian stunting, sehingga pada penelitian ini ditambahkan variabel pola asuh makan untuk melihat praktik pemberian makan yang dilakukan oleh ibu.

Kabupaten Klaten merupakan salah satu kabupaten yang masuk kedalam 100 kota/kabupaten prioritas stunting. ${ }^{20}$ Kabupaten Klaten terdiri dari 26 kecamatan dan kecamatan bayat merupakan salah satu kecamatan yang mempunyai prevalensi stunting yang tinggi yaitu 21,07\%. Penelitian terkait keragaman pangan, pola asuh makan dan kejadian stunting pada balita belum banyak dilakukan di Kabupaten Klaten khususnya Kecamatan Bayat. Berdasarkan hal tersebut maka tujuan penelitian ini adalah untuk mengetahui hubungan antara keragaman pangan dan pola asuh makan dengan kejadian stunting pada balita usia 24-59 bulan di Kecamatan Bayat, Kabupaten Klaten.

\section{BAHAN DAN METODE}

Desain penelitian yang digunakan adalah cross sectional study. Penelitian ini dilakukan di wilayah Kecamatan Bayat, Kabupaten Klaten pada bulan April 2018. Lokasi penelitian dipilih secara purposive dengan mempertimbangkan bahwa Kecamatan Bayat mempunyai prevalensi stunting yang tinggi, setelah itu dipilih tiga desa yang mempunyai prevalensi stunting tinggi yaitu desa Wiro, Banyuripan, dan Jarum. Populasinya adalah seluruh balita yang berusia 24-59 bulan. Besar subjek dihitung dengan menggunakan 
rumus perhitungan slovin, sehingga diperoleh subjek sebanyak 100 balita. $^{21}$

Teknik pemilihan subjek dengan menggunakan simple random sampling. Balita yang termasuk kedalam kriteria inklusi dipilih kemudian dilakukan pengacakan. Kriteria inklusi pada penelitian ini adalah anak tidak sedang dalam perawatan medis pada saat penelitian, tinggal bersama orang tua, bertempat tinggal di Kecamatan Bayat, balita berusia antara 24-59 bulan dan memiliki buku Kesehatan Ibu dan Anak/ KIA.

Data yang digunakan pada penelitian ini adalah data primer dan sekunder. Data primer diperoleh melalui wawancara dengan ibu balita dengan menggunakan kuesioner dan pengukuran langsung kepada balita seperti data pola asuh makan, keragaman pangan serta data pengukuran tinggi badan. Data sekunder diperoleh dari data balita yang terdapat diposyandu dan puskesmas serta data BBL (Berat Badan Lahir) dan PBL (Panjang Badan lahir) yang ada di buku Kesehatan Ibu dan Anak/ KIA. Tinggi badan diukur dengan menggunakan Microtoise dengan ketelitian $0,1 \mathrm{~cm}$.

Variabel terikatnya adalah status gizi berdasarkan tinggi badan menurut usia. Status gizi dikategorikan menjadi 2 yaitu yaitu stunting (pendek) jika status gizi berdasarkan TB/U mempunyai nilai z-score <-2SD dan normal jika status gizi berdasarkan TB/U mempunyai nilai z-scorenya $\geq-2$ SD. ${ }^{22}$ Variabel bebasnya yaitu jenis kelamin, berat badan lahir, panjang badan lahir, pola asuh makan dan keragaman makan. Berat badan lahir dikategorikan menjadi 2 yaitu berat badan lahir rendah jika $<2500$ gram dan normal apabila $\geq 2500$ gram. Panjang badan lahir dibedakan menjadi dua yaitu rendah jika panjang badan lahir $<48 \mathrm{~cm}$ dan apabila $\geq 48 \mathrm{~cm}$ berarti normal. $^{2}$

Pola asuh makan pada penelitian ini meliputi riwayat pemberian ASI dan MP-ASI serta praktek pemberian makan. Pola asuh makan diukur dengan menggunakan pertanyaan tertutup yang terdiri dari pertanyaan favourable dan unfavourable. Untuk pertanyaan favourable jawaban "ya" diberikan nilai 1 dan "tidak" diberikan nilai 0. Sedangkan pada pertanyaan unfavourable jawaban "ya" diberikan nilai 0 dan "tidak" diberikan skor 1. Kuesioner pola asuh makan dimodifikasi dari penelitian yang dilakukan oleh Martianto (2011) dan Nabuasa et al. (2013). ${ }^{6,7}$ Setelah dimodifikasi kemudian dilakukan uji validitas dan realibilitas dengan nilai cronbach's alpha 0,676 . Setelah itu pola asuh makan dikategorikan menjadi 2 yaitu kurang (jika skor pola asuh makan <60\%) dan baik (jika skor pola asuh makan $>60 \%$ ). Keragaman pangan diukur dengan menggunakan metode recall, setelah itu datanya dimasukkan pada kuesioner IDDS (Individual Dietary Diversity Score) yang terdiri dari 9 kelompok pangan. Jika Scorenya 0-5 maka dikategorikan makanannya tidak beragam, tetapi jika skornya lebih dari 5 maka disebut beragam. ${ }^{9}$

Analisis yang digunakan adalah analisis bivariat dan multivariat dengan menggunakan program SPSS. Analisis bivariat digunakan untuk mengetahui hubungan antara variabel terikat (dependen) dan variabel bebas (independent). Sedangkan analisis multivariat dipakai untuk mengetahui nilai OR (Odd Ratio). Analisis bivariat yang digunakan adalah uji chi square, sedangkan analisis multivariat yang dipakai adalah regresi logistik. Jika nilai $\mathrm{p}$ value pada analisis bivariat kurang dari 0,25 maka variabel tersebut dapat diikutkan pada uji regresi logistik. Penelitian ini sudah mendapatkan Ethical Clearance dari Komisi Etik Penelitian Kesehatan RSUD Dr. Moewardi dengan Nomor : 328/ III/ HREC/ 2018.

\section{HASIL}

\section{Karakteristik Subjek}

Jumlah subjek pada penelitian ini berjumlah 100 balita dan rata-rata subjek berusia 40 bulan dan mempunyai berat badan lahir 3000 gram. Rata-rata subjek mempunyai panjang badan lahir $<48 \mathrm{~cm}$, namun pada data maksimal terlihat ada subjek yang termasuk kedalam kategori panjang badan lahir normal. Rata-rata status gizi subjek tergolong dalam kategori normal dan mempunyai pola asuh makan yang baik. Jika dilihat dari keragaman pangannya, rata-rata subjek mempunyai keragaman pangan dengan skor 4,8. Nilai Minimal, Maksimal, Mean dan Standar Deviasi Karakteristik Subjek disajikan pada Tabel 1.

Tabel 1. Nilai Minimal, Maksimal, Mean dan Standar Devisiasi Karakteristik Subjek

\begin{tabular}{lccc}
\hline & Minimal & Maksimal & Mean \pm SD \\
\hline Usia (bulan) & 25 & 58 & $40 \pm 9,3$ \\
Berat Badan Lahir (gram) & 1700 & 4200 & $3000 \pm 0,5$ \\
Panjang Badan Lahir (cm) & 39 & 54 & $47,9 \pm 2$ \\
Z-score TB/U & -3.6 & 1,6 & $-1,6 \pm 1,1$ \\
Pola Asuh Makan & 27,3 & 100 & $65,9 \pm 16,4$ \\
Keragaman Pangan & 2,5 & 7 & $4,8 \pm 1,1$ \\
\hline
\end{tabular}

Sumber : Data Primer (2018) 


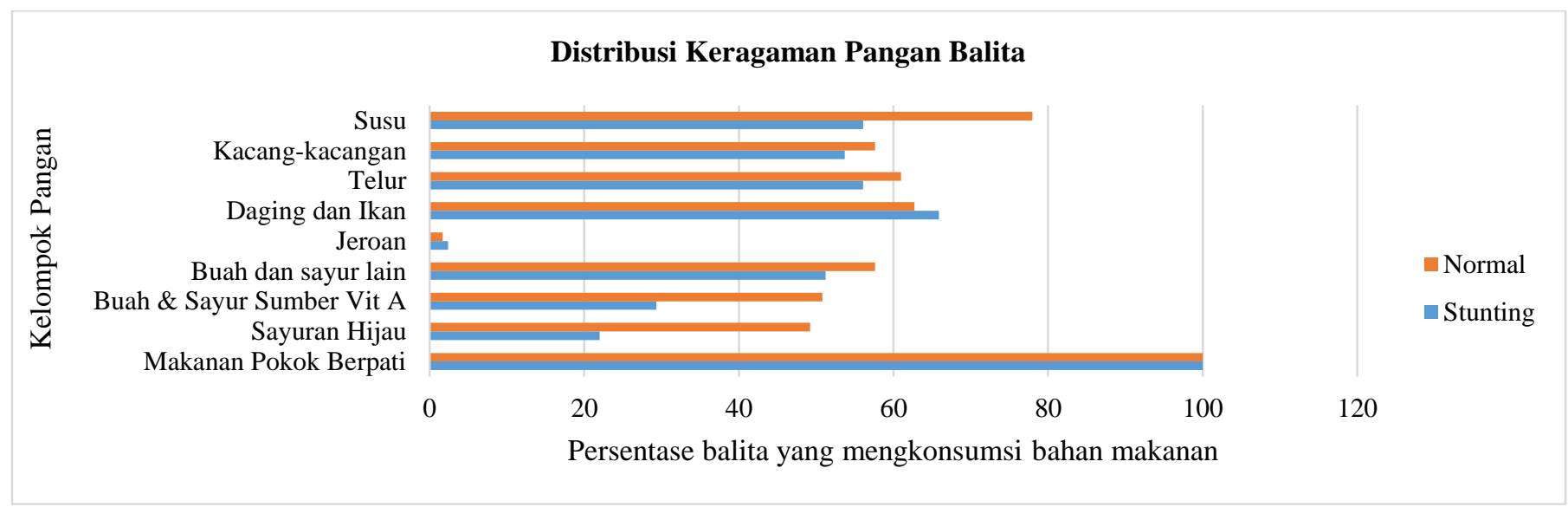

Gambar 1. Distribusi Keragaman Pangan Balita

Terkait dengan distribusi keragaman pangan balita, Gambar 1 menunjukkan bahwa balita yang berstatus gizi normal mempunyai asupan gizi yang lebih beragam jika dibandingkan balita yang mengalami stunting. Pada penelitian ini asupan makan balita stunting didominasi makanan sumber energi dan rendahnya asupan sayur, buah serta susu. Makanan sumber energi yang banyak dikonsumsi oleh balita stunting adalah beras, mie dan jagung, sedangkan makanan yang minoritas dikonsumsi adalah jeroaan. Balita stunting memiliki asupan sayur hijau, sayur dan buah sumber vitamin A, sayur lainnya, telur, kacangkacangan, dan susu yang lebih rendah jika dibandingkan dengan balita yang berstatus gizi normal. Pada penelitian ini persentase balita stunting yang mengkonsumsi daging dan ikan lebih tinggi $(65,9 \%)$ jika dibandingkan dengan balita yang berstatus gizi normal $(62,7 \%)$, tetapi selisihnya hanya $3,2 \%$.

\section{Analisis Bivariat}

Tabel 2 menunjukkan bahwa persentase balita stunting yang berjenis kelamin laki-laki $(58,5 \%)$ lebih tinggi jika dibandingkan dengan balita stunting yang berjenis kelamin perempuan $(41,5 \%)$. Persentase balita stunting yang mempunyai berat badan lahir $<2500$ gram adalah $22 \%$, sedangkan persentase balita stunting yang panjang badan lahirnya $<48 \mathrm{~cm}$ adalah $46,3 \%$. Jika dilihat dari pola asuh makan yang dilakukan oleh ibu, persentase balita stunting yang mempunyai pola asuh makan kurang $(51,2 \%)$ lebih banyak jika dibandingkan dengan balita stunting yang mempunyai pola makan yang baik $(48,8 \%)$. Sebanyak $85,4 \%$ balita stunting mempunyai asupan makan yang tidak beragam dan $53,7 \%$ balita stunting mendapatkan ASI kurang dari 6 bulan. Hasil uji chi-square menunjukkan bahwa ada hubungan yang signifikan antara panjang badan lahir, pola asuh makan dan keragaman pangan dengan stunting $(p \leq 0,05)$.

Tabel 2. Karakteristik Subjek pada Balita Stunting dan Normal

\begin{tabular}{lccccc}
\hline \multicolumn{1}{c}{ Karakteristik Subjek } & \multicolumn{2}{c}{ Stunting } & \multicolumn{2}{c}{ Normal } & Uji Chi-Square \\
\cline { 2 - 4 } $\boldsymbol{p}$ value
\end{tabular}




\section{Analisis Multivariat}

Dari hasil analisis chi-square variabel yang masuk kedalam analisis regresi logistik $(p<0,25)$ adalah variable berat badan lahir, panjang badan lahir, pola asuh makan dan keragaman pangan. Pada saat analisis regresi logistik dengan menggunakan metode Backward Wald, variabel berat badan lahir dikeluarkan dari model akhir uji regresi logistik sehingga hasil analisis regresi logistik menunjukkan faktor resiko kejadian stunting pada balita yang paling dominan adalah keragaman pangan $(p \leq 0,05)$ dengan nilai OR adalah sebesar 3,213. Hasil uji regresi logistik faktor resiko kejadian stunting disajikan pada Tabel 3.

Tabel 3. Hasil Uji Regresi Logistik Faktor Resiko Stunting pada Balita Usia 24-59 Bulan

\begin{tabular}{|c|c|c|c|c|c|}
\hline \multirow{2}{*}{ Variabel } & \multirow{2}{*}{$\boldsymbol{\beta}$} & \multirow{2}{*}{$p$} & \multirow{2}{*}{ OR } & \multicolumn{2}{|c|}{ Tingkat Kepercayaan } \\
\hline & & & & Batas Bawah & Batas Atas \\
\hline Keragaman Pangan & 1,167 & $0,029 *$ & 3,213 & 1,123 & 9,189 \\
\hline Pola Asuh Makan & 0,894 & 0,051 & 2,446 & 0,997 & 5,997 \\
\hline Panjang Badan Lahir & 0,804 & 0,085 & 2,234 & 0,896 & 5,570 \\
\hline Konstanta & $-1,007$ & 0,001 & 0,365 & & \\
\hline
\end{tabular}

Sumber : Data Primer (2018)

\section{PEMBAHASAN}

\section{Karakteristik Subjek}

Hasil penelitian ini menunjukkan bahwa persentase balita yang mengalami stunting adalah $41 \%$. Menurut WHO, suatu wilayah dikatakaan mengalami masalah gizi serius jika prevalensi balita pendek lebih dari $40 \% .^{22}$ Persentase balita stunting usia 24-59 bulan yang berjenis kelamin laki-laki dan perempuan yaitu $58,5 \%$ dan $41,5 \%$. Hasil uji chi square menunjukkan bahwa tidak terdapat hubungan yang bermakna antara jenis kelamin dengan kejadian stunting. Hasil penelitian ini diperkuat dengan penelitian yang dilakukan oleh Rukmana et al bahwa tidak ada hubungan yang bermakna antara jenis kelamin dengan kejadian stunting. Balita yang berjenis kelamin laki-laki dan perempuan mempunyai peluang yang sama untuk mengalami stunting. ${ }^{23}$ Hasil berbeda ditemukan pada penelitian di Nigeria, Mozambique, Afrika Tengah dan Ethiopia bahwa jenis kelamin merupakan faktor penyebab terjadinya stunting. Balita yang berjenis kelamin lakilaki memiliki peluang lebih besar untuk mengalami stunting jika dibandingkan perempuan. ${ }^{4,24-29}$ Balita lakilaki mempunyai aktivitas bermain yang lebih aktif jika dibandingkan perempuan, kondisi ini jika tidak diimbangin dengan asupan gizi yang cukup maka dapat menyebabkan terjadinya stunting. ${ }^{30}$ Perbedaan hasil penelitian ini terjadi karena pada penelitian ini balita laki-laki mempunyai asupan makan yang lebih beragam jika dibandingkan dengan balita perempuan, meskipun balita laki-laki mempunyai aktivitas bermain yang lebih aktif tetap diimbangi dengan asupan gizi yang memadai.

Kebiasaan ibu ketika hamil akan berpengaruh terhadap Berat Badan Lahir (BBL) dan Panjang Badan Lahir (PBL). Ibu yang mempunyai pola makan yang buruk akan melahirkan bayi dengan BBL dan PBL yang rendah. Hasil penelitian ini menunjukkan bahwa balita stunting yang memiliki BBL $<2500$ gram adalah $22 \%$ dan $78 \%$ balita stunting memiliki BBL normal. Hasil uji chi-square menunjukkan bahwa tidak terdapat hubungan yang bermakna antara BBL dengan kejadian stunting pada balita. Penelitian sebelumnya telah melaporkan bahwa BBL bukan faktor resiko stunting pada balita. Hal ini terjadi karena pengaruh BBL terjadi pada 6 bulan pertama kehidupan, kemudian menurun sampai usia 24 bulan. Dengan demikian jika bayi dapat mengejar pertumbuhan mereka dalam 6 bulan pertama kehidupan maka ada kemungkinan besar untuk mencapai tinggi badan normal. ${ }^{31}$

Hasil berbeda ditemukan pada penelitian yang dilakukan pada anak usia 12-23 bulan bahwa BBLR merupakan salah faktor resiko kejadian stunting. ${ }^{32}$ Baduta yang yang memiliki riwayat BBLR memiliki resiko 5,87 kali untuk menderita stunting jika dibandingkan dengan baduta yang lahir dengan berat lebih dari 2500 gram. ${ }^{33}$ Hasil penelitian yang dilakukan oleh Rahayu et al pada anak usia 6-24 bulan menunjukkan bahwa anak baduta yang mempunyai riwayat BBLR memiliki peluang 5,6 kali lebih besar untuk mengalami stunting dibandingkan baduta yang lahir dengan berat badan normal. ${ }^{33}$

Terkait dengan panjang badan lahir lahir sebanyak 46,3\% balita stunting memiliki panjang badan lahir $<48$ $\mathrm{cm}$ dan sebanyak $53,7 \%$ balita stunting memiliki panjang badan lahir $\geq 48 \mathrm{~cm}$. Uji chi square menunjukkan bahwa ada hubungan yang bermakna antara PBL dengan stunting $(p \leq 0,05)$. Penelitian sebelumnya telah melaporkan bahwa balita yang mempunyai riwayat PBL rendah $(<48 \mathrm{~cm})$ berpeluang 5,9 kali menjadi stunting pada usia 12 bulan jika dibandingkan dengan balita yang mempunyai riwayat PBL normal. ${ }^{34}$ Hasil penelitian yang sama juga ditunjukkan pada penelitian yang dilakukan di Kabupaten Brebes bahwa anak yang mempunyai riwayat panjang badan rendah mempunyai resiko 6,29 kali lebih besar untuk mengalami stunting. ${ }^{35}$ Hasil penelitian yang dilakukan di NTB mengungkapkan bahwa balita yang mempunyai panjang lahir kurang dari $47 \mathrm{~cm}$ memiliki resiko 2,14 kali lebih besar untuk mengalami stunting. ${ }^{36}$ 


\section{Hubungan Pola Asuh Makan dengan Stunting}

Kejadian stunting pada balita selain dipengaruhi oleh karakteristik balita juga dipengaruhi oleh faktor lain seperti pola asuh makan. Pada Tabel 2 dapat dilihat bahwa sebanyak $51,2 \%$ balita stunting memiliki pola asuh makan yang kurang, dan uji chi square menunjukkan bahwa terdapat hubungan yang bermakna antara pola asuh makan dengan kejadian stunting $(p \leq 0,05)$. Hasil penelitian ini diperkuat dengan penelitian yang dilakukan di Nusa Tenggara Timur bahwa ada hubungan antara pola asuh dengan stunting pada balita usia 24-59 bulan. Balita yang mempunyai riwayat pola asuh kurang memiliki peluang 14,5 kali mengalami stunting jika dibandingkan dengan balita yang mempunyai riwayat pola asuh yang baik. ${ }^{7}$ Hasil penelitian yang dilakukan di Kabupaten Aceh Tengah menunjukkan bahwa pola asuh merupakan faktor resiko kejadian stunting dengan nilai OR 8,07, hal ini menunjukkan bahwa balita dengan pola asuh kurang memiliki peluang 8 kali lebih besar untuk mengalami stunting, jika dibandingkan dengan balita dengan pola asuh baik. ${ }^{37}$

Rendahnya pola asuh asuh menyebabkan buruknya status gizi balita. ${ }^{37}$ Jika hal ini terjadi pada masa golden age maka akan menyebabkan otak tidak dapat berkembang secara optimal dan kondisi ini sulit untuk dapat pulih kembali. Pola asuh yang kurang dalam penelitian ini adalah pada indikator praktek pemberian makan. Ibu yang memiliki anak stunting memiliki kebiasaan menunda ketika memberikan makan kepada balita. Selain itu, ibu memberikan makan kepada balita tanpa memperhatikan kebutuhan zat gizinya. Kondisi ini menyebabkan asupan makan balita menjadi kurang baik dari segi kualitas maupun kuantitasnya sehingga balita rawan mengalami stunting. Hasil penelitian yang dilakukan oleh Sari \& Ratnawati menyatakan bahwa ada hubungan antara praktik pemberian makan kepada balita dengan status gizi. Praktik pemberian makan berhubungan dengan kualitas konsumsi makanan yang pada akhirnya akan meningkatkan kecukupan zat gizi. Tingkat kecukupan zat gizi merupakan salah satu faktor yang dapat mempengaruhi status gizi balita. ${ }^{38}$

Pada indikator riwayat pemberian ASI dan MP ASI mayoritas balita stunting dan normal memiliki riwayat pemberian ASI dan MP ASI yang hampir sama. Hasil penelitian ini menunjukkan bahwa tidak terdapat hubungan antara pemberian ASI Eksklusif ( $\geq 6$ bulan) dengan kejadian stunting. Hal ini terjadi karena pemberian ASI eksklusif yang lebih dari 6 bulan akan menunda pemberian MP ASI, sehingga balita akan mendapatkan asupan zat gizi yang kurang. Kondisi ini akan mengganggu pertumbuhan dan perkembangan balita karena setelah balita berusia 6 bulan, pemberian ASI harus didampingi dengan pemberian MP ASI karena ASI tidak cukup untuk memenuhi kebutuhan zat gizi balita. ${ }^{39}$

\section{Hubungan Keragaman Pangan dengan Stunting}

Keragaman pangan merupakan gambaran dari kualitas makanan yang dikonsumsi oleh balita. Tabel 1 menunjukkan bahwa rata-rata skor keragaman pangan pada penelitian ini adalah 4,8. Kondisi ini menunjukkan bahwa asupan makan balita di Kecamatan Bayat termasuk kedalam kategori tidak beragam, karena skor keragaman pangan kurang dari 5..$^{9}$ Hasil penelitian sebelumnya yang dilakukan di Nigeria dan Cina menyatakan bahwa rata-rata skor keragaman pangan pada balita dikedua Negara tersebut adalah 6,04 dan 6,8. ${ }^{17,40}$ Hasil tersebut lebih tinggi jika dibandingkan dengan penelitian yang di lakukan di Indonesia. Hal ini terjadi karena adanya perbedaan pola makan dan keadaan sosial ekonomi antara Negara yang satu dengan yang lainnya. Penelitian sebelumnya menyebutkan bahwa keadaan sosial ekonomi berhubungan dengan konsumsi pangan, semakin tinggi pendapatan maka semakin beragam makanan yang dikonsumsi. ${ }^{18}$

Tabel 2 menunjukkan bahwa sebanyak 85,4\% balita yang asupan makannya tidak beragam mengalami stunting dan hanya $14,6 \%$ balita yang asupan makannya beragam yang mengalami stunting. Uji chi square menunjukkan bahwa terdapat hubungan yang bermakna antara keragaman pangan dengan kejadian stunting pada balita $(p \leq 0,05)$. Jika dilihat dari distribusi kelompok pangan yang dikonsumsi terdapat kecenderungan bahwa balita stunting memiliki asupan sayur hijau, sayur dan buah sumber vitamin A, sayur dan buah lainnya, kacangkacangan, dan susu yang lebih rendah jika dibandingkan dengan balita yang berstatus gizi normal. Persentase balita stunting yang mengkonsumsi daging dan ikan lebih tinggi jika dibandingkan dengan balita yang berstatus gizi normal, tetapi selisihnya hanya 3,2\%.

Penelitian yang dilakukan di Gresik menunjukkan bahwa asupan sayuran hijau seperti bayam dapat menurunkan resiko kejadian stunting, karena sayuran hijau banyak mengandung zat besi yang berfungsi untuk mencegah terjadinya stunting. Asupan zat besi yang diperoleh dari makanan apabila jumlahnya berlebihan maka akan disimpan dalam otot dan sumsum tulang belakang. Jika kecukupan zat besi tidak memadai maka zat besi yang disimpan dalam tulang belakang digunakan untuk memproduksi hemoglobin menurun. Jika kondisi ini berlangsung secara terus menerus maka akan mengakibatkan anemia besi dan menurunkan kekebalan tubuh, sehingga mudah terserang penyakit infeksi yang dalam jangka panjang akan berdampak pada pertumbuhan liner balita. ${ }^{41}$ Penelitian sebelumnya yang dilakukan di Iran menunjukkan bahwa balita yang memiliki asupan susu yang rendah memiliki peluang lebih besar untuk mengalami stunting karena susu banyak mengandung kalsium yang berfungsi untuk mendorong pertumbuhan tinggi badan balita. ${ }^{42}$

Hasil uji multivariate dengan menggunakan regresi logistik menunjukkan bahwa terdapat hubungan 
antara keragaman pangan dengan kejadian stunting pada balita. Balita yang mempunyai asupan pangan yang tidak beragam memiliki resiko 3,213 kali untuk mengalami stunting jika dibandingkan dengan balita yang mempunyai asupan pangan yang beragam $(p=0,029$, $\mathrm{OR}=3,213,95 \% \mathrm{Cl}: 1,123-9,189)$. Hasil penelitian ini sama dengan penelitian yang dilakukan oleh Paramashanti et al di Kabupaten Bantul, Yogyakarta pada anak usia 6-24 bulan bahwa Skor Individual Dietary diversity Score (IDDS) sangat terkait dengan kejadian stunting. Baduta yang asupan keragaman pangannya rendah memiliki 16,67 peluang lebih besar untuk mengalami stunting dibandingkan dengan baduta yang asupan keragaman makanannya tinggi. ${ }^{19}$

\section{SIMPULAN}

Dari hasil pembahasan diatas dapat disimpulkan bahwa terdapat hubungan antara panjang badan lahir, pola asuh makan dan keragaman pangan dengan kejadian stunting pada balita usia 24-59 bulan di Kecamatan Bayat. Faktor resiko kejadian stunting yang paling dominan adalah keragaman pangan. Balita yang mempunyai asupan pangan yang tidak beragam memiliki 3,213 kali untuk mengalami stunting jika dibandingkan dengan balita yang mempunyai asupan pangan yang beragam. Berdasarkan kondisi tersebut maka sejak bayi perlu dikenalkan dengan berbagai macam macam sayur dan buah, sehingga ketika dewasa anak tidak akan melakukan penolakan terhadap makanan tersebut.

\section{UCAPAN TERIMA KASIH}

Penulis mengucapkan terima kasih kepada Badan Penyuluhan dan Pengembangan Pertanian Sumber Daya Manusia Pertanian, Kementerian Pertanian yang telah membiayai penelitian ini dan responden yang telah bersedia untuk dijadikan subjek. Ucapakan terima kasih juga disampaikan kepada Direktur Pascasarjana Universitas Sebelas Maret, Kepala Program Studi Ilmu Gizi Pascasarjana Universitas Sebelas Maret, Kepala Dinas Kesehatan Kabupaten Klaten, Kepala Puskesmas Kecamatan Bayat, Ahli Gizi Puskesmas Kecamatan Bayat, Bidan Desa wilayah Puskesmas Kecamatan Bayat serta semua pihak yang turut berpartisipasi pada penelitian ini.

\section{DAFTAR PUSTAKA}

1. UNICEF. Improving Child Nutrition: The Achievable Imperative for Global Progress. New York: United nations Plaza; 2013.

2. Kementerian Kesehatan. Riset Kesehatan Dasar (RISKESDAS) 2013. Jakarta: Kementerian Kesehatan RI; 2013.

3. Kementerian Kesehatan. Buku Saku Pemantauan
Status Gizi Tahun 2017. Jakarta: Direktorat Jenderal Kesehatan Masyarakat, Kementerian Kesehatan; 2018.

4. Garcia Cruz LM, Gonzalez Azpeitia G, Reyes Suarez D, Rodriguez Santana A, Loro Ferrer JF, Serra-Majem L. Factors associated with stunting among children aged 0 to 59 months from the central region of Mozambique. Nutrients. 2017;9(5):1-16.

5. Hardianti R, Dieny FF, Wijayanti HS. Picky eating dan status gizi pada anak prasekolah. J Gizi Indones. 2018;6(2).

6. Martianto D, Riyadi H, Ariefiani R. Pola Asuh Makan Pada Rumah Tangga Yang Tahan Dan Tidak Tahan Pangan Serta Kaitannya Dengan Status Gizi Anak Balita Di Kabupaten Banjarnegara. J Gizi dan Pangan. 2011;6(1):51-58.

7. Nabuasa, C.D, Juffrie, M, dan Huriyati E. Riwayat pola asuh, pola makan, asupan zat gizi berhubungan dengan stunting pada anak 24-59 bulan di Biboki Utara, Timor Tengah Utara, Nusa Tenggara Timur. J Gizi dan Diet Indones. 2013;1(3):31-43.

8. Baliwati $\mathrm{Y}$ farida, Briawan $\mathrm{D}$, Melani $\mathrm{V}$. Pengembangan Instrumen Penilaian Kualitas Konsumsi Pangan pada Rumah Tangga Miskin di Indonesia. Gizi Indones. 2015;38(1):63-71.

9. Kennedy G, Ballard T, Dop M. Guidelines for Measuring Household and Individual Dietary Diversity. Roma (IT): FAO; 2011.

10. Ochola S, Masibo PK iny. Dietary intake of schoolchildren and adolescents in developing countries. Ann Nutr Metab. 2014;64:24-40.

11. Labadarios D, Zandile June-Rose Mchiza NPS, Gericke G, Eleni Maria Winifred Maunder YDD, Paker W. Food security in South Africa: a review of national surveys. Bull World Health Organ. 2011;89:891-899.

12. Li Y, Lai J, He Y, et al. Lack of dietary diversity and dyslipidaemia among stunted overweight children: The 2002 China National Nutrition and Health Survey. Public Health Nutr. 2011;14(5):896903.

13. Ey Chua EY, Zalilah MS, Ys Chin YS NS. Dietary diversity is associated with nutritional status of Orang Asli children in Krau Wildlife Reserve, Pahang. Malays J Nutr. 2012;18(1):1-13.

14. Mestuti K, Fitranti DY. Faktor Risiko Kejadian Overweight Pada Anak Stunting Usia Sekolah Dasar Di Semarang Timur. J Nutr Coll. 2014;3(1):134-141.

15. Dewey KG, Begum K. Long-term consequences of stunting in early life. Matern Child Nutr. 2011;7(SUPPL. 3):5-18.

16. M'Kaibi FK, Steyn NP, Ochola SA, Du Plessis L. The relationship between agricultural biodiversity, dietary diversity, household food security, and 
stunting of children in rural Kenya. Food Sci Nutr. 2017;5(2):243-254.

17. Ukegbu P, Ogu VO. Assessment of Dietary Diversity Score, Nutritional Status and Sociodemographic Characteristics of Under-5 Children in Some Rural Areas of Imo State, Nigeria. Malays J Nutr. 2017;23(3):425-435.

18. Wirawan N, Rahmawati W. Ketersediaan dan Keragaman Pangan serta Tingkat Ekonomi sebagai Prediktor Status Gizi Balita. Indones J Hum Nutr. 2016;3(1):80-90.

19. Paramashanti BA, Paratmanitya Y, Marsiswati. Individual dietary diversity is strongly associated with stunting in infants and young children. J Gizi Klin Indones. 2017;14(1):19-26.

20. Tim Nasional Penanggulangan Kemiskinan. 100 Kabupaten/ Kota Prioritas Untuk Intervensi Anak Kerdil (Stunting). Jakarta: Sekretariat Wakil Presiden RI; 2017.

21. Notoatmodjo S. Metodelogi Penelitian Kesehatan. Jakarta: Rineka Cipta; 2012.

22. World Health Organization. Nutrition Landscape Information System: Country Profile Indicator, Interpretation Guide. Geneva: World Health Organization; 2012.

23. Rukmana E, Briawan D, Ekayanti I. Faktor Risiko Stunting Pada Anak Usia 6-24 Bulan Di Kota Bogor. Media Kesehat Masy Indones. 2016;12(3):192-199.

24. Akombi BJ, Agho KE, Hall JJ, Merom D, AstellBurt T, Renzaho AMN. Stunting and severe stunting among children under-5 years in Nigeria: A multilevel analysis. BMC Pediatr. 2017;17(1):1-16.

25. Vonaesch P, Tondeur L, Breurec S, et al. Factors associated with stunting in healthy children aged 5 years and less living in Bangui (RCA). PLoS One. 2017;12(8).

26. M yalew B. Prevalence and Factors Associated with Stunting, Underweight and Wasting: A Community Based Cross Sectional Study among Children Age 6-59 Months at Lalibela Town, Northern Ethiopia. J Nutr Disord Ther. 2014;04(02).

27. Fikadu T, Assegid S, Dube L. Factors associated with stunting among children of age 24 to 59 months in Meskan district, Gurage Zone, South Ethiopia: A case-control study. BMC Public Health. 2014;14(1):1-7.

28. Tessema, Belachew, Ersino. Feeding patterns and stunting during early childhood in rural communities of Sidama South Ethiopia. Pan Afr Med J. 2013;14:1-12.

29. Ahmadi D, Amarnani E, Sen A, Ebadi N, Cortbaoui $\mathrm{P}$, Melgar-Quiñonez $\mathrm{H}$. Determinants of child anthropometric indicators in Ethiopia. BMC Public Health. 2018;18(1):1-9.
30. Rosha BC, Hardinsyah H, Baliwati YF. Analisis Determinan Stunting Anak 0-23 Bulan Pada Daerah Miskin Di Jawa Tengah Dan Jawa Timur. Penelit Gizi dan Makanan. 2012;35(1):34-41.

31. Nasution D, Nurdiati DS, Huriyati E. Berat badan lahir rendah (BBLR) dengan kejadian stunting pada anak usia 6-24 bulan. J Gizi Klin Indones. 2014;11(1):31-37.

32. Aryastami NK, Shankar A, Kusumawardani N, Besral B, Jahari AB, Achadi E. Low birth weight was the most dominant predictor associated with stunting among children aged 12-23 months in Indonesia. BMC Nutr. 2017;3(1):16.

33. Rahayu A, Yulidasari F, Putri AO, Rahman F. Riwayat Berat Badan Lahir dengan Kejadian Stunting pada Anak Usia Bawah Dua Tahun. Kesmas Natl Public Heal J. 2015;10(2):67.

34. Ernawati F, Rosmalina Y, Permanasari Y. Pengaruh Asupan Protein ibu hamil dan panjang bayi lahir terhadap kejadian stunting pada anak usia 12 bulan di kabupaten bogor. Penelit Gizi dan Makanan. 2013;36(1):1-11.

35. Wellina WF, Kartasurya MI, Rahfilludin MZ. Faktor risiko stunting pada anak umur 12-24 bulan. J Gizi Indones. 2016;5(1):55-61.

36. Trimukti WY, Huang Y-W, Amini A. Affecting Factors of Stunting Incidences among Children Aged 12-59 Months in West Nusa Tenggara Province Indonesia. J Healthc Commun. 2017;2(4):45.

37. Aramico B, Sudargo T, Susilo J. Hubungan Sosial Ekonomi, Pola Asuh, Pola Makan dengan Stunting Pada Siswa Sekolah Dasar di Kecamatan Lut Tawar, Kabupaten Aceh Tengah. J Gizi dan Diet Indones. 2013;1(3):121-130.

38. Sari MRN, Ratnawati LY. Hubungan Pengetahuan Ibu tentang Pola Pemberian Makan dengan Status Gizi Balita di Wilayah Kerja Puskesmas Gapura Kabupaten Sumenep. Amerta Nutr. 2018:182-188.

39. Paramashanti BA, Hadi H, Gunawan IMA. Pemberian ASI eksklusif tidak berhubungan dengan stunting pada anak usia 6-23 bulan di Indonesia. J Gizi dan Diet Indones (Indonesian J Nutr Diet. 2016;3(3):162.

40. Zhao W, Yu K, Tan S, et al. Dietary diversity scores: An indicator of micronutrient inadequacy instead of obesity for Chinese children. BMC Public Health. 2017;17(1):1-11.

41. Dewi E, Nindya T. Hubungan Tingkat Kecukupan Zat Besi Dan Seng Dengan Kejadian Stunting Pada Balita 6-23 Bulan. Amerta Nutr. 2017;1(4):361.

42. Esfarjani F, Roustaee R, Mohammadi-nasrabadi F, Esmaillzadeh A. Major Dietary Patterns in Relation to Stunting among Children in Tehran, Iran. J Heal Popul Nutr. 2013;31(2):202-210. 